$17^{\text {th }}$ International Congress of Metrology, 03007 (2015)

DOI: $10.1051 /$ metrology $/ 201503007$

(C) Owned by the authors, published by EDP Sciences, 2015

\title{
The new method for calibration and testing of the bell type prover
}

\author{
Jurij Tonkonogij ${ }^{1, a}$, Arūnas Stankevičius ${ }^{1}$, Agnė Bertašiené ${ }^{1}$ and Andrius Tonkonogovas ${ }^{1}$ \\ ${ }^{1}$ Lithuanian energy institute, Breslaujos 3, 44403, Kaunas, Lithuania
}

\begin{abstract}
Résumé. Les installations de référence de type cloche sont largement utilisés comme un étalon primaire de flux d'air. La nouvelle méthode de l'étalonnage de l'installation est développée. La méthode est basée sur la mesure simultanée de signaux d'impulsions à haute fréquence de déplacé par le volume d'air de la cloche et la cloche de déplacement. Proposé méthode assure une évaluation détaillée du volume déplacé spécifique ainsi que la distribution de débit le long de la hauteur de la cloche. L'avantage important du procédé est son application à l'installation de cloche assemblé. Cela simplifie essentiellement la utilisant des résultats d'étalonnage. La méthode prend en compte non seulement la section de la variabilité, mais aussi l'influence de la variation de la pression. Les résultats de expérimental sont qualitativement en bon accord avec la simulation numérique.
\end{abstract}

\section{Introduction}

The bell type provers are widely used as a primary standard of air flow volume $[1,2]$

One of the most common methods of such facilities calibration is the geometric method, when the bell crosssection area distribution along its height is being measured. This method provides good accuracy, but technically is rather difficult, especially in the cases of big bells Furthermore, the method does not ensure consideration of the effect of pressure variability. The method is described in detail in [3]

The main goal of bell prover calibration is to evaluate the link between the bell displacement $d H$ and the displaced air volume $d V_{\text {air }}$. The volume of displaced air at actual temperature and pressure values equal to the change in the volume non-immersed part of the bell $d V_{\text {bell }}$.

The main goal of bell prover calibration is to evaluate the link between the displaced air volume $d V_{\text {air }}$ and the bell displacement $d H$. The volume of displaced air at actual temperature and pressure values is equal to change of the volume of non-immersed part of the bell $d V_{\text {bell }}$.

The character of the link is well known, it is linear. The coupling coefficient $k_{V} \equiv d V / d h$ specifies the value of displaced air volume per unit of the bell displacement. In ideal case the coefficient $k_{V}$ is equal to the bell crosssection. In reality it slightly along the bell height due the inconstancy of bell cross-section along the height, which in its turn is caused by insufficient perfection of the bell manufacturing techniques.

The second important factor affecting coefficient $k_{V}$ is constancy of the pressure in the bell. If the air pressure is constant, a local value of the coefficient coincides with the local value of the cross section. If the air pressure is

\footnotetext{
a Corresponding author: Jurij.Tonkonogij@lei.lt
}

changing the coefficient varies differently than bell crosssection

Coefficient $k_{V}$ sometimes is called specific displaced volume.

On the base of numerical simulation is shown that the bell movement is essentially uneven [4]. Pressure and the displaced air volume fluctuate during bell displacement. It was experimentally confirmed that bell speed, displaced air volume and pressure are inconstant $[5,6]$. Data on the impact of variable pressure on the specific displaced volume in the available sources are absent.

We developed a new method of calibration based on the simultaneous measurement of high-frequency pulse signals of displaced by the bell air volume and of the bell displacement. As well as geometric method, the offered method ensures detailed measurement of the specific displaced air volume distribution along the bell height, more accurate, during bell displacement. New method surpasses geometric one in labor inputs. Unlike the geometric method, the new method allows taking into account pressure inconstancy. The important advantage of the method is its application to the assembled bell facility. This essentially simplifies the using of the calibration results.

\section{Experimental technique}

The measurement scheme for realization of the method is presented in Figure 1.

For measuring of air volume it's advisable to use ADUO type rotary gas meter, the size of which depends on the size of the bell. This meter has good repeatability and can be calibrated with an uncertainty up to $\pm(0.1-0.12)$ $\%$. Unlike a turbine gas meter that was used in [5] the rotary gas meter has of one order faster response. 
During the adjustment on a special bench with the sonic nozzles it was tested uniformity of rotors rotating and., respectively, the uniformity of the output signal, which were better than $0.01 \%$.

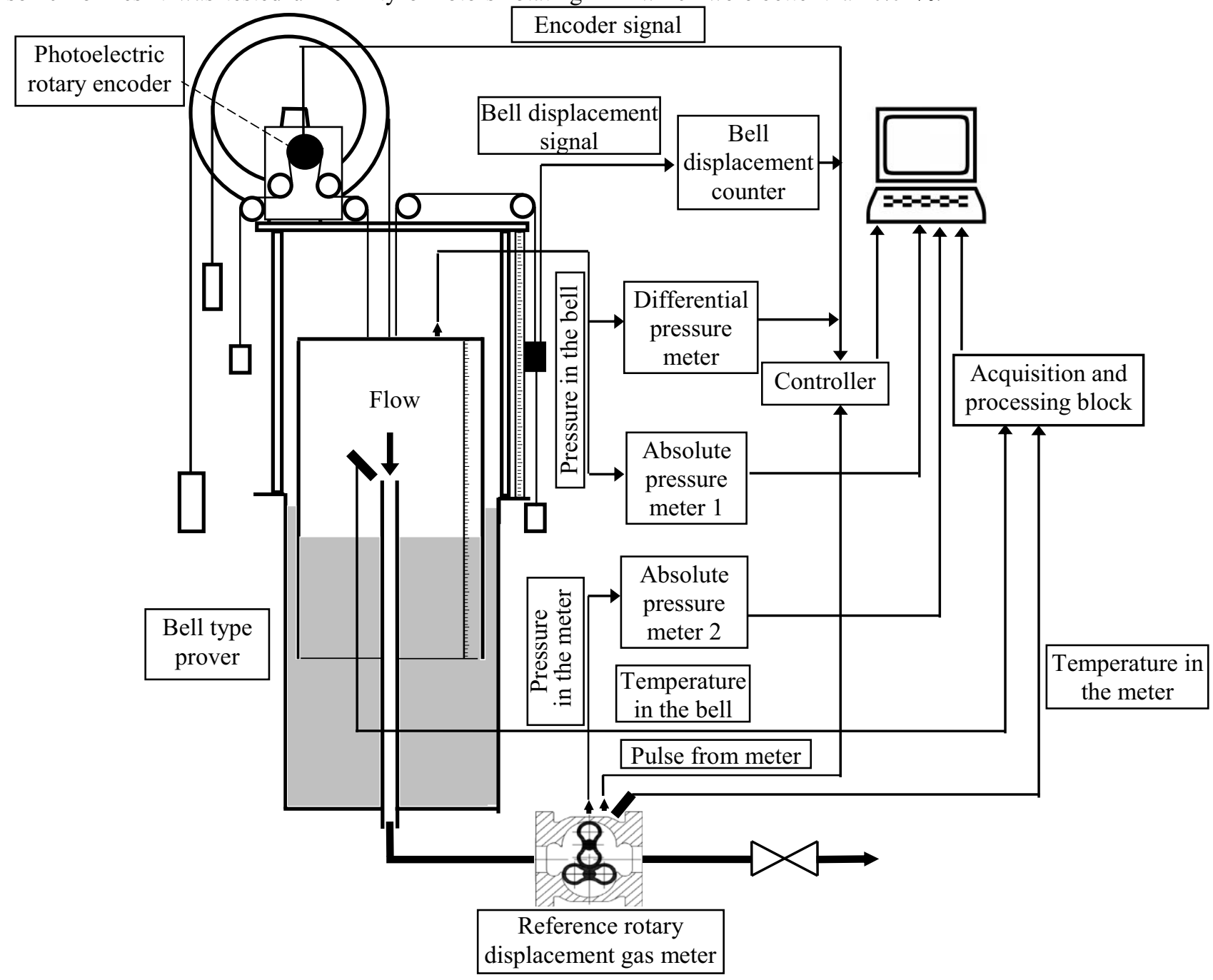

Figure 1. The scheme of facility.

The number of the pulses for full bell displacement should be not less than $200-500$.

To ensure a sufficiently low uncertainty of calibration the number of pulses of bell's displacement signal for every registered air volume should not be less than $10^{4}$. This means that the number of pulses corresponding to the full bell displacement should be of order $(2-3) \cdot 10^{6}$. In particular, we used the A90H type encoder of company PRECIZIKA METROLOGY, 450,000 pulses on 1 revolution.

The special mechanical system for kinematical conjunction of the bell and encoder has been developed.

Beside the bell and the meter pulses, temperatures and pressures for volume conversion should be measured. All measurements are synchronized respecting to gas meter's pulses. The time of every measurement should be registered.

For diagnostics of the technical condition of the bell facility it's important to know the variation of gauge pressure with the bell displacement. This pressure should be measured by fast response pressure transducer simultaneously with other specified quantities. We used
DP103 type membrane pressure transducer of VALIDYNE manufacturing.

The distribution of flow rate and specific volume (uniquely connected with bell cross-section) can be obtained by processing of measurement results. Offered method ensures uncertainty of calibration up to $\pm(0.12$ $0.15) \%$.

\section{Results and discussion}

Some results of application of the method to the bell with diameter of $0.63 \mathrm{~m}$ and effective height of $1 \mathrm{~m}$ are presented on the following plots. These results are obtained for average value of flow rate $Q_{a v}=1.6 \mathrm{~m}^{3} / \mathrm{h}$.

Figure 2 shows the change in the relative displaced air flow rate (ratio of instant $O_{i}$ and average along height $Q_{a v}$ values), and the corresponding change in differential pressure in the moving bell as well.

First of all, it should be noted very good compliance of these two curves. It corresponds to the one of the general concepts of hydrodynamics concerning dependence flow rate on the acting differential pressure. 
Flow rate fluctuates periodically. It may be noted two major frequency fluctuations in flow rate. Lower frequency, which value is of the order $(0.01-0.015) \mathrm{Hz}$ corresponds to fluctuation of bell displacement. Larger value, of the order $(0.1-0.15) \mathrm{Hz}$, corresponds to periodic force interaction of moving parts bell facility, such as bearings, cables, pulleys, etc. Of course, parameters of fluctuation vary significantly depending on the design, size, technical condition of the facility, as well as on average value of air flow rate.

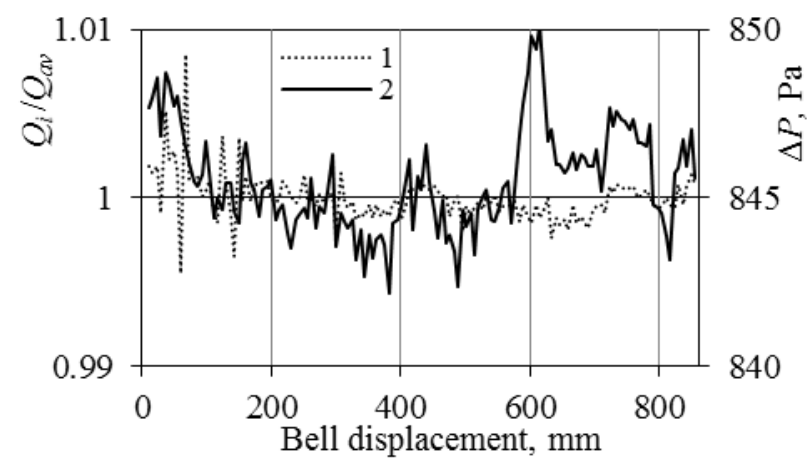

Figure 2. Change in relative flow rate and pressure. 1 - relative flow rate; 2 - differential pressure in the meter.

All told is also fully refers to the character of change in pressure.

Figure 3 shows the change in specific displaced volume.

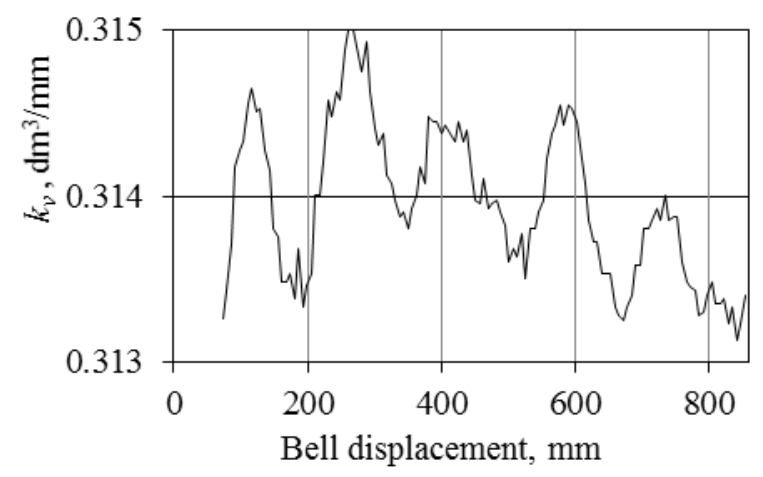

Figure3. Change in specific displaced volume.

Character of change in specific displaced volume (first of all frequency pulsation) is similar to the flow rate and pressure. However, the magnitude of change varies somewhat differently. The cause of this is not only an effect of change in pressure, but also inconstancy of cross-section.

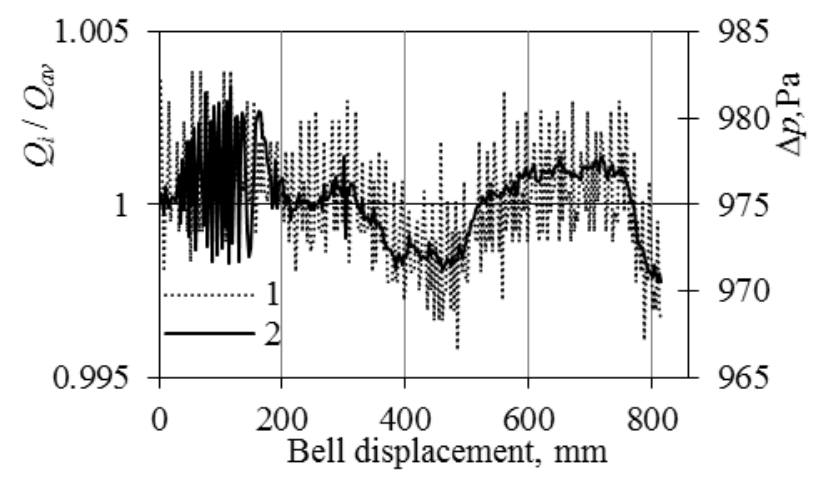

Figure 4.Change in relative flow rate and pressure before facility adjusting. 1 - relative flow rate; 2 - differential pressure in the meter.

Obtained results can be used for evaluation displaced air volume and flow rate during normal operation

Presented experimental results are qualitatively in good agreement with numerical simulations [4].

Use of obtained results allows to diagnose malfunctions and disturbances of the technical condition and to take measures for them eliminating, as well as to improve the facility.

For example, in Figure 4 and Figure 5 the same dependences, as in Figure 2 and figure 3 are presented, only before the elimination due to the use of the described method detected drawbacks.

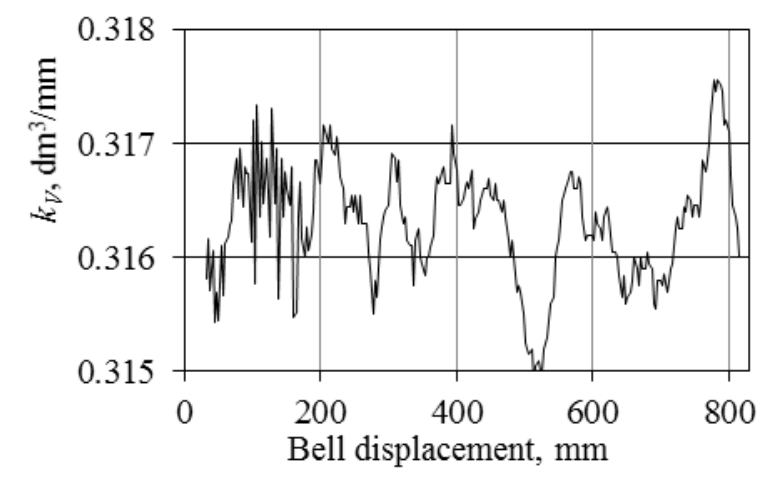

Figure 5. Change in specific displaced volume before facility adjusting.

Figures 4 and 5 clearly manifests increased in comparison with Figures 2 and 3 fluctuations in all displayed parameters, which disappeared after eliminating drawbacks.

\section{Conclusions}

1. The new method of bell type prover calibration and testing was developed.

2. The method allows to obtain distribution of all important parameters along the bell height.

3. Evaluation of specific displaced volume is specific displaced volume is performed taking into account not only not only bell cross-section distribution but pressure distribution as well

4. The method allows to diagnose technical condition of the facility and its technical perfection.

\section{References}

1. GMG PTB-100. Gasmessglocke (bell prover) bauart PTB

2. Wright J. D., Mattingly G. E. NIST Special Publication 250-49. (1998)

3. Benkova M., Makovnik S., Mikulecky I., Zamecnik V. J. Metr. Soc. Ind. 26, 165 (2011)

4. Ruegg F. W., Ruegg F. C. J. Res. Natl. Inst. Stand Technol. 95, 15, (1990)

5. Mihalic T., Stasic, T., Degiuli N. XVII IMEKO World Congress. 1402 (2003)

6. Darie C., Tanase A. MECAHITECH'12. 92 (2012) 